\title{
TEORIZANDO SOBRE A MIGRAÇÃO DE RETORNO: UMA ABORDAGEM CONCEITUAL REVISITADA SOBRE MIGRANTES DE RETORNO*
}

Jean-Pierre Cassarino**

\begin{abstract}
A diversidade de categorias migratórias (variando de migrantes econômicos a refugiados e solicitantes de asilo) exige a desagregação dos vários tipos de retornados. Ainda precisamos saber quem retorna, quando e por quê; e por qual razão alguns migrantes retornados aparecem como atores de mudança, em circunstâncias sociais e institucionais específicas em sua pátria, enquanto outros não. $\mathrm{O}$ primeiro objetivo deste trabalho é analisar como o retorno vem sendo tratado pelas teorias de migração internacional, enfatizando particularmente os pressupostos nos quais elas se baseiam. Esta abordagem teórica é necessária para mostrar como o retorno vem sendo definido e localizado no tempo e no espaço, e como o migrante retornado tem sido descrito. O segundo objetivo é dar um passo à frente nas várias abordagens da migração de retorno, por meio do aprofundamento de conhecimentos teóricos que têm sido propostos até agora. Será, então, apresentada uma abordagem conceitual revisitada aos migrantes retornados, levando-se em conta um conjunto de critérios de distinção, quais sejam, a "return preparedness" e a "mobilização de recursos".
\end{abstract}

Palavras-chave: migrações de retorno, teorias, return preparedness, recursos, capital humano, redes sociais.

\section{Introdução}

A migração de retorno, enquanto elemento constitutivo da migração internacional, foi objeto de várias abordagens especulativas, que oferecem uma série de interpretações às vezes antitéticas, pois derivam de teorias

\footnotetext{
* Este artigo foi originalmente publicado na revista International Journal on Multicultural Societies, v. 6, n. 2, 2004, p. 253-279. Tradução do inglês: Equipe CSEM.

** Professor no Robert Schuman Centre for Advanced Studies, European University Institute. Florença/ Itália.
} 
contrapostas entre elas, tais como: a Economia Neoclássica, a New Economics of Labour Migration, o Estruturalismo, o Transnacionalismo e a Teoria das Redes Sociais. Do ponto de vista qualitativo, numerosas investigações empíricas foram realizadas com o objetivo de ilustrar a multiplicidade dos fatores que fazem da migração de retorno um fenômeno complexo e heterogêneo. Apesar desta variedade de interpretações, a migração de retorno, em nossa visão, não é, ainda hoje, objeto de fácil e clara leitura, não tanto por negligência dos estudiosos - a migração de retorno foi objeto de numerosas análises acadêmicas a partir dos anos 1960 - mas porque a sua magnitude e configuração são dificilmente mensuráveis e comparáveis, devido à falta de dados quantitativos confiáveis em larga escala.

$\mathrm{Na}$ atualidade, a atenção dada pelas organizações internacionais à ligação entre migração e desenvolvimento tem evidenciado a necessidade de se reexaminarem as abordagens teóricas à migração de retorno. A crescente diversidade de categorias migratórias (variando de migrantes econômicos a refugiados e solicitantes de asilo) exige a desagregação dos vários tipos de migrantes retornados. É de fundamental importância saber quem retorna, quando e por quê; e por qual razão alguns retornados aparecem como atores de mudança, em circunstâncias sociais e institucionais específicas em sua pátria, enquanto outros não conseguem exercer este papel.

Como pré-requisito para apresentar uma abordagem conceitual revisitada dos perfis dos retornados, levando em conta um conjunto de critérios de distinção, o primeiro objetivo deste trabalho é analisar como o retorno tem sido tratado pelas teorias de migração internacional, enfatizando particularmente os pressupostos nos quais elas se baseiam. Esta abordagem teórica é necessária para mostrar como o retorno vem sendo definido e localizado no tempo e no espaço, e como o migrante retornado tem sido descrito.

O segundo objetivo é dar um passo à frente nas várias abordagens da migração de retorno, por meio do detalhamento de conhecimentos teóricos que têm sido propostos até agora. Será, então, apresentada uma abordagem conceitual revisitada aos retornados, levando-se em conta um conjunto de critérios de distinção, quais sejam, a "return preparedness" e a "mobilização de recursos". Estes critérios serão submetidos a um exame no desenvolvimento deste texto.

\section{Uma abordagem teórica à migração de retorno}

Ainda que a atenção do mundo acadêmico verse sobre a migração de retorno desde os anos 1960, não há dúvida de que, em retrospectiva, foi nos anos 1980 que se desenvolveu um debate científico sobre o fenômeno do 
retorno e seu impacto nos países de origem. Tal debate culminou na produção de vários ensaios críticos e na organização de conferências internacionais. ${ }^{1}$

Não há dúvida de que estes debates trouxeram uma substancial contribuição ao desenvolvimento da literatura sobre migrações de retorno e incrementaram o interesse para temas como o "codesenvolvimento", o "repatriamento voluntário de cidadãos de outros países", a emergência e a aplicação dos acordos bilaterais de readmissão entre países de origem e de acolhida e a relação entre migrações internacionais e desenvolvimento econômico nos países de proveniência dos migrantes.

É preciso sublinhar que a crescente variedade de estudos científicos, bem como a intensa politização dos movimentos migratórios internacionais, incidiram na maneira com a qual a migração de retorno e os retornados foram compreendidos e analisados. Inesperadamente, como indicado por Mary Kritz ${ }^{2}$, existem problemas de ordem conceitual a respeito das definições dos imigrantes, as quais influenciam a formulação de políticas nacionais de imigração; ademais, a pluralidade de definições da migração de retorno e dos migrantes retornados tem um papel fundamental para orientar, se não para plasmar, as percepções, as taxonomias e as políticas adotadas pelos vários entes governamentais e intergovernamentais.

Todas as teorias que serão apresentadas a seguir contêm intuições válidas, independentemente de suas opiniões e interpretações. Mesmo diferenciando-se entre si em termos analíticos sua validade é inerente à relevância da questão das migrações de retorno no interior de seus respectivos sistemas de referência.

Como pré-requisito para explorar a maneira mediante a qual o retorno tem sido caracterizado pelos teóricos da migração internacional, é importante ressaltar que os aprofundamentos teóricos discutidos abaixo, em vários níveis, incluíram a migração de retorno como um subcomponente de suas abordagens teóricas. Enquanto alguns desses aprofundamentos são resultado de estudos empíricos, outros são derivados da coleção fragmentada de dados quantitativos, baseada no critério de definição dado para o retorno.

A revisão crítica focaliza exclusivamente teorias que tentaram propor um conjunto de variáveis com o intuito de melhor entender a magnitude e as dinâmicas da migração de retorno para os países de origem. Independentemente de suas visões e interpretações, todas as teorias

\footnotetext{
${ }^{1}$ KUBAT, Daniel (ed.). The Politics of Return. International Return Migration in Europe; COUNCIL OF EUROPE, 4 June 1987. Third Conference of European Ministers Responsible for Migration Affairs: Conclusions.

${ }^{2}$ KRITZ, Mary M. International Migration Policies: Conceptual Problems, p. 948.
} 
apresentadas a seguir produziram aprofundamentos valiosos. Elas, até agora, se diferenciam entre si em termos de nível de análise e com respeito à relevância do tema do retorno em seus respectivos quadros analíticos.

\section{Economia Neoclássica e New Economics of Labour Migration (NELM)}

Dado que a abordagem neoclássica da migração internacional se fundamenta sobre a noção de diferenças salariais entre países de destino e aqueles de origem e sobre as expectativas dos migrantes a respeito de melhores ganhos nos países de acolhida ${ }^{3}$, o retorno é percebido como o resultado do fracasso de uma experiência migratória que não produziu os resultados esperados. Dito de outra forma, segundo a ótica neoclássica, a migração de retorno diz respeito unicamente aos trabalhadores migrantes que calcularam de forma errada os custos da emigração e que não alcançaram o aumento esperado da própria renda. O regresso à pátria ocorre, portanto, como consequência de suas experiências de fracasso no exterior ou então porque seu capital humano não foi recompensado como esperado. Por outro lado, contrariamente à New Economics of Labour Migration (veja mais adiante), a teoria neoclássica considera o migrante um indivíduo que tende a maximizar não só a própria renda, mas também a duração da própria permanência no exterior, com o objetivo de obter a residência definitiva e a reunificação familiar no país de acolhida. Segundo esse modelo de análise, o retorno ao próprio país de origem pode ser motivado pelo fracasso da própria experiência migratória em termos de renda, ocupação e duração.

Por outro lado, enquanto a abordagem neoclássica à migração de retorno afirma que o migrante não conseguiu maximizar com sucesso os ganhos esperados, a New Economics of Labour Migration (NELM) considera que o regresso é resultado de uma "estratégia calculada", que é definida no nível do núcleo familiar do migrante e motivada pelo fato de ter alcançado os objetivos pré-fixados. De fato, como afirma Oded Stark em sua importante publicação, a abordagem teórica proposta pela NELM "muda o foco central da teoria da migração da independência individual [...] para a interdependência recíproca" ${ }^{4}$, ou seja, ao nível familiar. Ainda, crê que o retorno à pátria seja a consequência natural de uma experiência migratória bem-sucedida, durante a qual os migrantes alcançaram os próprios objetivos (ou seja, maior renda e acúmulo de poupança), enviando parte dos ganhos à família. As remessas são partes integrantes de uma estratégia voltada para diversificar a economia

\footnotetext{
${ }_{3}$ TODARO, Michael P. A Model of Labor Migration and Urban Unemployment in Less Developed Countries, p. 140.

${ }^{4}$ STARK, Oded. The Migration of Labor, p. 25.
} 
do núcleo familiar com o objetivo de suprir os possíveis riscos ligados à ausência de um sistema de segurança social e de welfare eficientes no país de origem. Elas também constituem um fator explicativo da decisão de retorno, juntamente com o apego à terra natal.

A respeito da correlação entre as remessas e a probabilidade de retorno, Amelie Constant e Douglas Massey, analisando os dados relativos à migração de retorno de trabalhadores imigrantes na Alemanha de 1984 a 1987, observaram que aqueles que enviam remessas à própria família que permaneceu na pátria pertencem ao segmento da população migrante com maior índice de emprego no país de acolhida; constataram, ainda, que possuir um parceiro no país de origem aumenta a probabilidade de retorno ${ }^{5}$. Em antítese ao modelo neoclássico, Oded Stark e seguidores ${ }^{6}$ consideram $^{-}$ a migração de retorno como parte de um projeto de migração preparado com cuidado, que não somente estimula a propensão dos migrantes a "empenhar-se com mais esforço para o trabalho [nos países de acolhida] do que os trabalhadores autóctones"7 e a economizar mais dinheiro que esses últimos ${ }^{8}$, mas os exorta também a um maior nível de socialização nos países de chegada e à aquisição de habilidades suplementares ou de experiências formativas de campo. Em outros termos, a probabilidade de uma volta à pátria influencia a aquisição de competências no exterior. Segundo a NELM, de fato, os migrantes vão ao exterior por um período de tempo determinado, isto é, até quando conseguem fornecer a suas famílias a liquidez e as economias esperadas. O planejamento do projeto migratório incide sobre os modelos comportamentais dos migrantes na sociedade de acolhida, bem como sobre o progresso profissional.

O ponto de contraposição marcante entre a abordagem Teórica da Economia Neoclássica e aquela sustentada pela NELM reside justamente nas suas interpretações antitéticas da migração de retorno. De fato, quando os economistas neoclássicos sustentam que os migrantes se deslocam permanentemente para o exterior a fim de aumentar e maximizar os próprios salários nos países de acolhida, a migração de retorno aparece necessariamente como um fracasso ou, até mesmo, como uma anomalia. Ao contrário, quando os teóricos da NELM defendem que as pessoas migram de forma temporária a fim de alcançar seus objetivos ou metas

\footnotetext{
${ }^{5}$ CONSTANT, Amelie; MASSEY, Douglas S. Return Migration by German Guestworkers: Neoclassical versus New Economic Theories, p. 27-28.

${ }^{6}$ TAYLOR, J. Edward (ed.). Development Strategy, Employment and Migration: Insights from Models

7 STARK, op. cit., p. 392.

${ }^{8}$ STARK, Oded; GALOR Oded. Migrants' Savings, the Probability of Return Migration and Migrants' Performance.
} 
nos países receptores, como uma condição para a volta para a pátria, o retorno é interpretado como um resultado positivo, ou, até mesmo, como uma consequência lógica. Os teóricos da NELM se contrapõem firmemente à imagem neoclássica do migrante de retorno fracassado: a duração da permanência no exterior é sabiamente medida segundo as necessidades do núcleo familiar em termos de welfare, poder de aquisição e poupança. Uma vez que essas necessidades sejam satisfeitas, a migração de retorno ocorre. Em outros termos, para os seguidores da NELM, o retorno tem implicações que vão "além de uma simples resposta a um diferencial salarial negativo"9.

No entanto, ainda que a posição das duas abordagens teóricas a respeito da migração de retorno seja antitética, ambas fornecem observações valiosas sobre as razões que motivam o indivíduo a emigrar e retornar à pátria. Os migrantes têm projetos ou estratégias bem definidos antes, durante e depois de sua experiência migratória. De fato, a presença da supracitada "estratégia calculada" é, segundo a NELM, um elemento que sublinha o fato de que a decisão migratória não pode ser considerada como "um ato de desespero ou de otimismo excessivo"10. Seja por enfrentarem graves falhas do mercado de trabalho na pátria, seja por necessidade de suprir a desigualdade salarial entre o país de origem e aqueles de destino, os migrantes, de fato, dão provas de desenvolvimento de capacidade de planejamento em resposta às incertezas do mercado.

Contudo, no que tange aos quadros analíticos, ambas as abordagens teóricas apresentam vários pontos fracos. O primeiro refere-se aos atores e a suas motivações de retorno, que parecem derivar unicamente de fatores financeiros ou econômicos, sem, porém, explicar devidamente como as remessas e as competências adquiridas são utilizadas nos países de origem. A segunda consiste em considerar os migrantes de retorno como portadores de renda estrangeira, ou "intermediários financeiros", como os definiria Edwad Taylor. Ademais, embora a Economia Neoclássica e a NELM tentem explicar, quando e por que seja tomada a decisão de retornar à pátria, não assinalam para onde os migrantes voltam. Pela falta de referência ao ambiente social, econômico e político para os quais os migrantes retornam, as experiências do retorno parecem isoladas umas das outras. Portanto, não somente não estamos em condições de entender como são planejadas e reformuladas as estratégias do retorno, como também permanece sem explicação a interação entre o migrante e o ambiente que vai além de seu núcleo familiar e de seu parentesco. Enfim, como será exposto na próxima seção, vários

\footnotetext{
${ }^{9}$ STARK, Oded. On the Microeconomics of Return Migration, p. 11.

${ }^{10}$ Ibidem, p. 26.
} 
estudos empíricos têm demonstrado de modo convincente que o paradigma sucesso/fracasso não pode fornecer uma explicação exaustiva do fenômeno da migração de retorno. Este paradigma, de fato, tende a isolar as decisões e as estratégias dos migrantes de retorno do seu ambiente social e político, sem colocá-las em correlação com os fatores contextuais presentes no país de origem.

O retorno à pátria do migrante, como afirma a teoria estruturalista, não é uma questão pessoal, mas principalmente um problema social e contextual condicionado por fatores situacionais e estruturais.

\section{A perspectiva estruturalista e a migração de retorno}

As descobertas empíricas e as intuições teóricas de antropólogos, sociólogos e geógrafos sociais têm dado essencial contribuição ao aperfeiçoamento da abordagem estruturalista à migração de retorno.

Segundo a abordagem estruturalista, o retorno não é analisado somente em função da experiência individual do migrante, mas também em relação aos fatores sociais e institucionais presentes no país de origem. De fato, o retorno é também uma questão relacionada ao contexto.

A abordagem estruturalista não se distancia daquela da NELM ao demonstrar o quanto são decisivos os recursos financeiros e econômicos que o migrante traz consigo de volta à pátria como parte da decisão de retorno e de reintegração no país de origem. O sucesso ou o fracasso do migrante de retorno é analisado correlacionando a "realidade" da economia e da sociedade do país de origem com as expectativas do migrante. O notável artigo de Francesco Cerase, sobre os migrantes italianos que regressaram dos Estados Unidos, fornece numerosos exemplos indicativos da complexidade das relações entre as expectativas dos migrantes de retorno e o contexto econômico e social (ou seja, a "realidade") de seu país de origem. Cerase ${ }^{11}$ identifica quatro tipos diferentes de migrantes, evidenciado suas aspirações, expectativas e necessidades.

$\mathrm{O}$ "retorno do fracasso" (return of failure) diz respeito aos migrantes que não conseguiram integrar-se no país de acolhida por causa de preconceitos e de estereótipos com que se depararam no exterior. As dificuldades em assumir um papel ativo na sociedade de acolhida ou de adaptar-se à sociedade do país hospedeiro são suficientemente sérias para motivar o retorno.

O "retorno conservador" (return of conservatism) compreende os migrantes que antes de emigrar planejavam o retorno à pátria com o

\footnotetext{
${ }^{11}$ CERASE, Francesco P. Expectations and Reality: a Case Study of Return Migration from the United States to Southern Italy.
} 
dinheiro suficiente para comprar terra, a fim de "libertar-se da odiosa subordinação aos proprietários das terras"12. Por causa destas aspirações e estratégias, os migrantes de retorno "conservadores" só tendem a satisfazer as próprias necessidades pessoais e aquelas de seus familiares. Esta categoria de migrantes não deseja alterar o ambiente social que deixam para trás com a emigração, mas, pelo contrário, contribuem para conservá-lo.

$\mathrm{O}$ "retorno de aposentadoria" (return of retirement) refere-se aos migrantes aposentados que decidem regressar ao país de origem e adquirir um pedaço de terra e uma casa onde poderão passar a velhice.

O "retorno inovador" (return of innovation) é, sem dúvida, a categoria mais dinâmica de migrantes de retorno segundo a tipologia proposta por Cerase. Refere-se aos atores "prontos a fazer uso de todos os meios e todas as novas competências adquiridas durante a própria experiência migratória"13, com a finalidade de alcançar os próprios objetivos no país de origem que, segundo eles, oferece mais oportunidades de realização dos sonhos pessoais. Cerase sublinha o fato de que estes migrantes se consideram inovadores, pois acreditam que as competências adquiridas no exterior, junto às economias poupadas, transformaram-nos em "portadores de mudança". Todavia, segundo Cerase, é improvável que essa categoria de migrantes possa realmente contribuir para as mudanças no país de origem por causa da resiliência de fortes relações de poder e de interesses adquiridos, que impedem aos inovadores de tomarem iniciativas que poderiam colocar em cheque a situação constituída e os tradicionais equilíbrios de poder.

A tipologia de Cerase é uma clara tentativa de demonstrar que os fatores situacionais e contextuais nos países de origem são pré-requisitos indispensáveis para a avaliação da experiência migratória de retorno em termos de sucesso ou de fracasso. As observações do autor têm contribuído sem dúvida de modo essencial na elaboração das teorias sucessivas a respeito dos migrantes e das migrações de retorno. Poucos anos depois, de fato, um estudo de George Gmelch, elaborado sobre a tipologia de Cerase, sublinha a necessidade de correlacionar as intenções de retorno expressas pelos migrantes com as motivações nas quais se baseiam. A decisão de retornar, seja esta concreta ou simplesmente desejada, incide sobre as expectativas do migrante em relação ao país de origem ${ }^{14}$. O retorno parece estar orientado pelas oportunidades que os migrantes esperam encontrar nos países de

12 Ibidem, p. 254.

13 Ibidem, p. 251.

${ }^{14}$ ROGERS, Rosemarie. Return Migration in Comparative Perspective; CALLEA, Saverio. Different Forms, Reasons and Motivations for Return Migration of Persons who Voluntarily Decide to Return to Their Countries of Origin; RICHMOND, Anthony H. Explaining Return Migration. 
origem, mas também pelas oportunidades já oferecidas no país receptor. Uma vez que os fatores situacionais e estruturais incidem sobre a decisão do retorno, segundo Gmelch, esta decisão não pode ser planejada de modo apropriado caso os migrantes estejam em condições de avaliar esses fatores situacionais somente a posteriori.

Caso os fatores situacionais sejam avaliados a posteriori, os migrantes são considerados "despreparados para o próprio retorno" 15 , pois os mesmos têm dificuldade de reunir as informações necessárias para garantir o sucesso da volta e adquirir maior consciência das mudanças sociais, econômicas e políticas que durante esse tempo se verificaram nos países de origem.

Qualquer que seja o nível de expectativas dos migrantes de retorno, a abordagem estruturalista sustenta que só raramente estas são reformuladas em função da realidade local e que, por causa da resistência dos interesses tradicionais adquiridos no país de origem, os migrantes possuem um limitado poder de inovação nas sociedades de proveniência. Os estruturalistas acrescentam que, se esta readaptação das expectativas não acontece, o migrante poderia levar em consideração a decisão de migrar novamente.

A abordagem estruturalista à migração de retorno é essencial para ilustrar quanto os fatores contextuais podem incidir sobre a capacidade de inovação dos migrantes de retorno e sobre sua propensão a se tornarem atores de mudanças. Não são somente as competências e o capital financeiro a plasmar as experiências de retorno, mas também as relações locais de poder, as tradições e os valores presentes no país de origem, que incidem fortemente sobre a capacidade do migrante em investir a própria experiência migratória na sua pátria.

Em contraste com os quadros teóricos da Economia Neoclássica e da NELM, a visão estruturalista está assentada sobre a avaliação da eventual capacidade, por parte do migrante de retorno, de influenciar a própria sociedade de origem depois de sua volta. Como foi assinalado acima, esse sistema de referência analítica estuda as possíveis consequências da migração de retorno nos países de proveniência considerando duas variáveis: tempo e espaço.

Como variável temporal, entende-se a duração da permanência no exterior por aquilo que diz respeito às mudanças que se verificam antes e depois da migração em relação à condição social dos migrantes retornados e à sua sociedade de origem. As mudanças que acontecem na sociedade de origem e o progresso profissional dos migrantes constituem fatores decisivos no processo da sua reintegração na pátria após o retorno. Como afirma W.

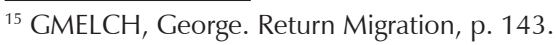


Dumon, "o migrante de retorno pode ser definido como uma pessoa que, a fim de ser aceita novamente, deve readaptar-se às mudanças de modelos comportamentais e culturais da própria comunidade de origem; pode-se nomear esse processo de ressocialização"16. A reinserção exige tempo, dependendo da duração da experiência migratória. Além disso, a duração da permanência no exterior deve ser otimizada a fim de que ao migrante seja permitido adquirir e diversificar as próprias habilidades, com vistas ao próprio investimento na pátria após o retorno ${ }^{17}$. Como sugere Russel King:

se [a duração da permanência] no exterior for muito breve, por exemplo, menos de um ano ou dois, o migrante terá adquirido pouca experiência para poder investi-la utilmente na promoção e modernização no próprio país. Se, ao invés, o período de ausência se prolongar por longo tempo, os migrantes de retorno poderão sentir-se tão "deslocados" no interior da sociedade de origem, ou ser tão avançados em idade, que terão neste caso também pouca influência sobre a sociedade. Entre esses dois extremos, pode-se encontrar uma permanência ideal no exterior, suficientemente prolongada para influenciar o migrante, consentindo-lhe assimilar determinadas experiências e valores, mas suficientemente breve de modo a permitir-lhe, depois do retorno, o tempo e a energia necessários para colocar em prática as habilidades e atitudes recentemente adquiridas ${ }^{18}$.

Quanto à variável espacial, os estruturalistas afirmam que a área de residência (rural ou urbana) determina o processo de reintegração dos migrantes de retorno e obriga-os a reformular as próprias expectativas. $\mathrm{O}$ estudo feito por Nora Colton sobre os migrantes iemenitas retornados da Arábia Saudita ilustra perfeitamente esse caso. A pesquisa por ela realizada na zona rural do lêmen demonstra que, mesmo que os migrantes de retorno tivessem melhorado o próprio teor de vida e aquele das suas famílias, eles não possuíam condições de "modificar os antigos valores de modo significativo" 19; eles tinham, ao contrário, a propensão a reafirmá-los. Colton relaciona esse fenômeno ao fato de que as grandes expectativas por parte do ambiente de retorno (família e amigos que permaneceram na pátria) incidem fortemente sobre as expectativas dos migrantes.

Enfim, segundo a visão estruturalista, uma vez que os migrantes de retorno modelam as próprias expectativas e os próprios comportamentos em relação às sociedades locais, para serem "re-aceitos", tendem a orientar os

\footnotetext{
${ }^{16}$ DUMON, Wilfried. Problems Faced by Migrations and their Family Members, Particularly Second Generation Migrants, in Returning to and Reintegrating into their Countries of Origin, p. 122.

${ }^{17}$ DUSTMANN, Christian. Return Migration, Wage Differentials, and the Optimal Migration Duration.

${ }^{18}$ KING, Russel (ed.). Return Migration and Regional Economic Problems, p. 19.

${ }^{19}$ COLTON, N. A. Homeward Bound: Yemeni Return Migration, p. 879.
} 
próprios modelos de consumo em investimentos improdutivos e ostensivos ${ }^{20}$. Ademais, os recursos são geralmente monopolizados pelos membros da família, que os investem na construção de grandes casas e na aquisição de carros de luxo, ao invés de utilizá-los, por exemplo, para renovar o maquinário agrícola. Estes padrões de consumo não fazem outra coisa além de reproduzir e perpetuar a diferença entre o centro (os países de acolhida) e a periferia (os países de procedência) - axioma básico da abordagem estruturalista à migração internacional, em geral, e àquela de retorno, em particular.

Graças à perspectiva estruturalista, a migração de retorno não é mais relacionada unicamente à experiência migratória do indivíduo no país de acolhida. Como sublinhado por Lewis e Williams em seu artigo sobre migrantes portugueses retornados, também a "localidade" (ou seja, o contexto local nos países de origem dos migrantes) exerce uma notável "influência sobre o impacto dos migrantes de retorno" ${ }^{21}$. Um contexto institucional favorável para as empresas, bem como o crescimento econômico dos países de origem, são essenciais para colocar em prática investimentos produtivos. As características institucionais presentes nos países de origem influenciam (negativamente ou positivamente) também o impacto das migrações de retorno sobre o desenvolvimento e o progresso social. Estes fatores contextuais serão posteriormente examinados na segunda parte desse estudo.

Antes que no fenômeno das migrações de retorno em si, os estruturalistas focalizam suas pesquisas em como as iniciativas dos migrantes poderiam favorecer o desenvolvimento econômico na pátria quando confrontado com as estruturas locais de poder. Tais teóricos tendem a limitar as experiências migratórias dos retornados à mera aquisição de habilidade - que na maioria das vezes são desperdiçadas por causa dos obstáculos estruturais inerentes à economia de proveniência - e à utilização dos capitais obtidos no exterior. Em outros termos, parece não haver um continuum entre a experiência migratória dos migrantes de retorno nos países de acolhida e a sua situação no país de origem. Além disso, o impacto dos recursos, sejam esses financeiros ou humanos, tangíveis ou intangíveis, permanece muito limitado na medida em que estão radicados no contexto familiar tradicional que define os padrões simbólicos e comportamentais aos quais o migrante de retorno está obrigado a adaptar-se se quiser ser novamente aceito em sua pátria.

O espírito de iniciativa dos migrantes retornados é avaliado com pessimismo pelos estruturalistas. Estes apresentam também uma visão parcial

\footnotetext{
${ }^{20}$ BYRON, Margaret; CONDON, Stephanie. A Comparative Study of Caribbean Return Migration from Britain and France: Towards a Context-Dependent Explanation, p. 100.

${ }^{21}$ LEWIS, Jim; WILLIAMS, Allan. The Economic Impact of Return Migration in Central Portugal, p. 125.
} 
da migração de retorno, cujo impacto é analisado segundo um sistema de referência verticalizado, no qual a realidade do país de origem aparece como o ator que estrutura as relações de poder locais e oferece mais oportunidades e ascensão social. Até mesmo o migrante de retorno inovador, descrito por Cerase, apresenta um retrato desestimulante das potencialidades humana e financeira dos migrantes de retorno: "Dois são os fatores que pesam sobre seu [do migrante de retorno inovador] fracasso: o primeiro é a economia do bairro ou da cidade de repatriação; o segundo, as relações de poder entre as várias classes que constituem estas comunidades"22.

Como conclusão, os migrantes retornados não conseguem alcançar os próprios objetivos porque permaneceram por muito tempo fora dos "modos tradicionais de pensar" das suas sociedades de origem, perdendo, ao mesmo tempo, o contato com as redes de relação social. Em outros termos, quando residem no exterior, os migrantes não continuam mantendo laços com seus países de origem.

Esta dicotomia entre centro e periferia assinala um conflito entre dois mundos distintos: de um lado, os países modernos de imigração, do outro, os países de origem tradicionais dos migrantes retornados. Esta dicotomia estrutural fortemente criticada por Rachel Murphy ${ }^{23}$ se fundamenta no pressuposto de que existe uma limitada troca de informações entre estes dois mundos e que o migrante de retorno não estará nunca em condições de mobilizar as habilidades e os recursos necessários para enfrentar as condições reais na sua pátria, com a esperança de facilitar a própria reintegração ${ }^{24}$. Como veremos a seguir, os transnacionalistas e os teóricos da Teoria das Redes Sociais questionam fortemente esses pressupostos.

\section{Transnacionalismo e migração de retorno}

O escopo desta seção não é tanto o de ilustrar a teoria transnacional, mas aquele de colocar em evidência os pressupostos sobre os quais se fundamenta quando trata o tema das migrações e dos migrantes de retorno.

Nos final dos anos 1980, na tentativa de ressaltar as dinâmicas e a manutenção de laços da migração regular entre países de proveniência e de acolhida - fato este muitas vezes esquecido pelos estruturalistas - e de dar uma interpretação aos movimentos fronteiriços das populações, alguns estudiosos das migrações, provenientes de várias disciplinas, começaram a adotar a terminologia transnacional que até então tinha sido utilizada

\footnotetext{
${ }^{22}$ CERASE, op. cit., p. 258.

${ }^{23}$ MURPHY, Rachel. How Migrant Labor is Changing Rural China.

${ }^{24}$ VELIKONJA, Joseph. Geography of Return Migration.
} 
pelos especialistas de Relações Internacionais. Sem nenhuma dúvida, este empréstimo terminológico tem proporcionado várias interpretações e entendimentos que gerou, não raramente, uma dose de negligência no uso e na pertinência analítica desta terminologia no campo da migração.

O Transnacionalismo se propõe a formular um modelo teórico e conceitual que visa uma melhor compreensão dos intensos laços sociais e econômicos existentes entre os países de acolhida e de origem dos migrantes. As atividades transnacionais acontecem, segundo Alejandro Portes, mediante "contatos sociais regulares, duradouros e intensos através das fronteiras nacionais" 25 . A teoria transnacional tenta explicar em que medida estes laços podem incidir sobre a identidade dos migrantes. Contrariamente ao que afirmam os estruturalistas e os partidários da NELM, o retorno à pátria não é o fim do ciclo migratório: segundo a visão transnacional, o fato migratório continua. A migração de retorno é, portanto, parte integrante de um sistema circular de relações sociais e econômicas e de trocas que facilitam a reintegração dos migrantes e, ao mesmo tempo, transmitem a estes últimos conhecimento, informação e sentimento de pertencimento. Um dos maiores pontos de desacordo entre os transnacionalistas e os estruturalistas reside no fato de que, segundo os primeiros, os migrantes de retorno preparam a própria reintegração na terra natal mediante visitas periódicas e regulares ao seu país de origem. Eles mantêm intensos laços com o país de proveniência e enviam remessas às próprias famílias com certa regularidade.

A base teórica transnacional, no que diz respeito à migração, se funda sobre dois campos de pesquisa correlacionados entre si: a identidade e a mobilidade transnacional.

As identidades transnacionais são resultado da combinação das origens dos migrantes com as identidades que estes adquirem no país de acolhida. Segundo os transnacionalistas, esta combinação é mais precursora de "identidades duais" que de identidade conflituosas, enquanto os migrantes são considerados indivíduos capazes de negociar o próprio lugar na sociedade, mirando a integração, seja nos países receptores seja na pátria. Contrariamente aos estruturalistas, que preferem falar de adequações, os transnacionalistas reconhecem a necessidade de uma "adaptação" na hora do retorno à pátria. Este processo de adaptação não implica no abandono da identidade adquirida no exterior. Certamente os migrantes de retorno devem enfrentar dificuldades de reintegração seja a nível social seja a nível profissional. Todavia, como assinalamos acima, os contatos regulares que eles mantêm com a família nos

25 PORTES, Alejandro et alii. The Study of Transnationalism: Pitfalls and Promise of an Emergent Research Field, p. 219. 
países de origem, juntamente com a realização de práticas recorrentes de conexão entre os dois pólos que testemunham uma mobilidade transnacional ${ }^{26}$, predispõem-nos a uma maior capacidade para organizar o próprio retorno. Ainda que se reconheça a capacidade de os migrantes avaliarem os custos e os benefícios do retorno, o impacto concreto com a realidade local na pátria - a nível social, econômico e político - pode dar lugar ao surgimento e à consolidação de identidades transnacionais, que por sua vez moldam os comportamentos e as expectativas dos migrantes de retorno.

Ainda no campo transnacional, o volume publicado por Nadje Al-Ali e Khalid Koser fornece uma visão esclarecedora de como o conceito de "terra natal", ou de "pátria", por parte do migrante, pode estar fundamentado sob várias formas de apego. Os migrantes podem, ao mesmo tempo, estar ligados à própria pátria e emotivamente apegados ao próprio lugar de nascimento, ou vice-versa. Segundo os transnacionalistas, a percepção subjetiva dos migrantes sobre a terra natal e sua auto-identificação com o lugar de origem têm uma influência sobre a decisão de retornar e sobre o processo de reintegração, uma vez que estas atitudes encerram em si um complexo substrato social e histórico. Por fim, Al-Ali e Koser afirmam que "outra característica dos migrantes transnacionais consiste no fato de que estes mantêm conexões econômicas, políticas e sociais que interligam várias sociedades. O que define o pertencimento a esta rede de conexões é a partilha de uma mesma origem, ou do mesmo país de proveniência" ${ }^{27}$. O sentido comum de pertencimento a uma etnia, a mesma origem e os laços de parentela parecem ser os fatores mais favoráveis à manutenção de atividades transnacionais e à definição das identidades transnacionais. Mesmo pertencendo a um grupo geograficamente disperso, os migrantes "se sentem coligados entre si graças a um lugar de proveniência comum e por laços religiosos e sociais partilhados" 28 .

O Transnacionalismo se propõe também a ilustrar como "o desenvolvimento de uma nova identidade entre os migrantes que não estão (socialmente, culturalmente e fisicamente) ancorados nem no lugar de proveniência nem naquele de destinação" tenha favorecido a gradual desterritorialização da cidadania. Esta afirmação controversa foi sustentada pela recorrente referência às "diásporas", ainda em voga entre os partidários do Transnacionalismo, mesmo que alguns deles estejam colocando em

\footnotetext{
${ }^{26}$ Ibidem.

${ }^{27}$ AL-ALI, Nadje; KOSER, Khalid (eds). New Approaches to Migration? Transnational Communities and the Transformation of Home, p. 10.

28 LEVITT, Peggy. Forms of Transnational Community and their Implications for Immigrant Incorporation: Preliminary Findings, p. 4.
} 
dúvida a sua pertinência analítica, limitando o seu uso às comunidades ${ }^{29}$ transnacionais altamente institucionalizadas ${ }^{30}$. Sem dúvida, este empréstimo terminológico antes que evidenciar os desejos dos migrantes de retornar ao país nativo (como induziria a crer a referência à diáspora), representa uma tentativa de demonstrar que "os governos dos países de proveniência procuraram, nos últimos anos, intensificar os contatos com as próprias diásporas para envolvê-las, de vários modos, na vida nacional"31. Além disso, falando das diásporas não se pode deixar de fazer referências à questão étnica.

O Transnacionalismo diz respeito também àquelas iniciativas orientadas a um objetivo, que são coordenadas a nível coletivo e que são progressivamente institucionalizadas em consequência de sua interação com os governos dos países de origem. Há muitos exemplos emblemáticos no mundo que demonstram como os governos dos países de origem estiveram prontos para reagir positivamente ao empoderamento político e econômico das comunidades emigradas ao exterior. Não raro, essas relações institucionalizadas têm "reconstituído os laços entre os emigrantes e o país nativo"32 mediante a criação de instituições estatais e entes para-estatais, com o objetivo de responder a questões econômicas, políticas e de segurança atinentes aos países de origem mais do que promover o retorno à pátria dos migrantes. Em verdade, este processo não é uma novidade na história das migrações internacionais ${ }^{33}$. Apesar disso, uma vez que o termo diáspora passou a fazer parte do léxico de muitos funcionários governamentais, é razoável crer que o mencionado processo de institucionalização das atividades transnacionais contribuiu para torná-las mais gerenciáveis, do ponto de vista econômico, e mais permeáveis às questões políticas ${ }^{34}$.

Na verdade, o Transnacionalismo não faz somente referência à manutenção de intensos laços entre os migrantes e as suas famílias no país de

\footnotetext{
${ }^{29}$ Referindo-se às diásporas, Thomas Faist prefere falar de "um tipo específico de comunidade transnacional". Ele sustenta que "não é útil aplicar o termo diáspora aos colonos ou aos trabalhadores migrantes, porque estes não viveram experiências traumáticas e não se pode inferir que a maioria dos membros destes grupos anseia regressar na pátria perdida" (FAIST, op. cit., p. 10).

${ }^{30}$ SCHNAPPER, Dominique. De I'Etat-nation au monde transnational. Du sens et de l'utilité du concept de diaspora, p. 31; FAIST, op. cit.

${ }^{31}$ PORTES, Alejandro. Introduction: The Debates and Significance of Immigrant Transnationalism, p. 190.

32 BRAND, Laurie. States and Their Expatriates: Explaining the Development of Tunisian and Moroccan Emigration-Related Institutions, p. 6; LEICHTMAN, Maria A. Transforming Brain Drain into Capital Gain: Morocco's Changing Relationship with Migration and Remittances.

${ }^{33}$ VERTOVEC, Stephen. Conceiving and Researching Transnationalism, p. 145.

${ }^{34}$ AL-ALI, Nadje; BLACK, Richard; KOSER, Khalid. The Limits of Transnationalism: Bosnian and Eritrean Refugees in Europe as Emerging Transnational Communities, p. 590-591.
} 
origem, mas também à multiplicidade de modos pelos quais os migrantes se sentem ligados entre si, devido às origens étnicas comuns e à solidariedade entre os membros de um mesmo grupo. Os seus recursos humanos e financeiros parecem estar radicados em um modelo de interação definido segundo parâmetros étnicos ${ }^{35}$. A abordagem transnacional às migrações internacionais tende a considerar a ação dos migrantes como consequência direta do seu pertencimento à própria comunidade migrante (dispersa). A solidariedade do grupo e os recursos são definidos em referência à comunidade transnacional na qual estão enraizadas as suas iniciativas e expectativas.

É importante sublinhar, como mostrado acima, que as práticas transnacionais são consideradas permeáveis à interferência governamental, por causa das suas crescentes institucionalizações. Ademais, considera-se que as identidades transnacionais são a consequência direta de práticas que se desenvolvem em uma espécie de espaço dual de identificação, abrangendo ambos os Estados nacionais do país de origem e de acolhida ${ }^{36}$.

Mesmo que os transnacionalistas concordem com a interação entre Estados nacionais e comunidades migrantes transnacionais, eles reconhecem também a necessidade de novas investigações com a finalidade de avaliar a extensão do impacto desta reciprocidade sobre a magnitude e a esfera de influência de ambas as entidades. Além disso, enquanto alguns deles sustentam que "o Transnacionalismo da imigração não é induzido por razões ideológicas, mas pela lógica do capitalismo global"37, outros, ao contrário, afirmam que "as comunidades transnacionais podem exercitar um notável poder político, econômico e social"38.

Além destas interpretações divergentes, é importante sublinhar que, no âmbito da migração de retorno, o Transnacionalismo permite destacar os laços transfronteiriços entre os migrantes de retorno e as suas comunidades no exterior. O regresso à pátria ocorre depois de ter recolhido os recursos financeiros ou as informações suficientes e ter a certeza de encontrar condições suficientemente favoráveis no país de origem. Na perspectiva transnacional, o

\footnotetext{
${ }^{35}$ HSING, You-Tien. Making Capitalism in China: The Taïwan Connection.

${ }^{36}$ Luis Eduardo Guarnizo sustenta que as práticas e as argumentações transnacionais não comprometem necessariamente o Estado nacional, enquanto as relações transnacionais estão estreitamente entrelaçadas com as estruturas estatais, seja nos países de proveniência, seja naqueles de acolhida. Ele acrescenta: "as práticas transnacionais estão para o nacionalismo como as práticas econômicas e informais estão para a economia formal. Por definição, essas são correlacionadas entre si de modo dialético: o desaparecimento de uma provoca o desaparecimento da outra. Afinal, as práticas transnacionais são possíveis somente em um sistema global de Estados nacionais" (GUARNIZO, Luis Eduardo. Notes on Dual Citizenship, Nationalism, and Transnational Migration).

${ }^{37}$ PORTES, op. cit., p. 187.

${ }^{38}$ AL-ALI, KOSER, op. cit., p. 12.
} 
retorno tem sido abordado levando em consideração os vários modos por meio dos quais os migrantes se adaptam com sucesso ao seu ambiente de origem em todos os níveis. Os migrantes sabem como tirar vantagem dos "atributos de identidades" adquiridos no exterior, a fim de distinguir-se dos demais co-nacionais. Eles podem ter que enfrentar pressões sociais ou então sentir-se marginalizados pela própria sociedade de proveniência, mas se esforçam para negociar o próprio lugar na sociedade sem negar as próprias especificidades.

Enfim, graças à abordagem transnacional referente às migrações internacionais, de modo geral, e à migração de retorno, em particular, é possível questionar a posição estruturalista binária dos movimentos transfronteiriços considerando a circularidade dos movimentos migratórios que agiliza a mobilidade dos migrantes ${ }^{39}$. Pode-se ainda afirmar que a referência ao termo "diáspora" constitui um modo de destacar a mobilidade multipolar dos migrantes.

Não obstante a indiscutível validade destas opiniões, é difícil entender como a manutenção de intensos laços com as próprias comunidades no exterior possa permitir aos migrantes retornados lidar melhor com os interesses tradicionais e as pressões sociais que caracterizam suas sociedades de proveniência. Ainda, à medida que os defensores do Transnacionalismo insistem nas identidades duplas e híbridas dos migrantes e na mobilidade transfronteiriça, a abordagem transnacional à migração de retorno corre o risco de confinar as iniciativas dos migrantes e seus projetos na pátria a um conjunto de obrigações, oportunidades e expectativas determinado unicamente pela etnia comum (diáspora) e pelos familiares (núcleo familiar).

Como foi explicado neste estudo, os aprofundamentos teóricos elaborados pelas teorias das redes permitem uma melhor exploração do modelo analítico da migração de retorno, transcendendo, ao mesmo tempo, a embeddedness da diáspora e os vínculos de consanguinidade. De fato, enquanto o Transnacionalismo considera o migrante de retorno como o sujeito que recolhe os recursos necessários para garantir e preparar a volta para a pátria, mobilizando recursos originados pelos atributos em comum (por exemplo, religião e pertencimento étnico), a Teoria das Redes Sociais considera os migrantes como atores que reúnem recursos necessários para garantir e preparar seu retorno à terra natal, por meio da mobilização de recursos decorrentes da comunhão de interesses e disponíveis a nível de redes sociais econômicas e transfronteiriças.

\footnotetext{
${ }^{39}$ CHAPMAN, Murray; PROTHERO, R. Mansell. Themes on Circulation in the Third World, p. 84.
} 


\section{Teoria das Redes Sociais e migrações de retorno}

Em concordância com a abordagem transnacional à migração de retorno, a Teoria das Redes Sociais sustenta que os migrantes de retorno são portadores de recursos tangíveis e intangíveis. Mesmo que seja difícil avaliar a priori o respectivo impacto destes recursos sobre as iniciativas dos migrantes de retorno, não se pode analisar a migração de retorno prescindindo desses elementos. Assim como a abordagem transnacional à migração de retorno, a Teoria das Redes Sociais reconhece a capacidade dos migrantes retornados de tecer intensos laços com as antigas áreas de assentamento no exterior. Todavia, estes laços não são atribuídos ao compartilhamento de atributos como foi assinalado anteriormente. Da mesma forma, não dependem necessariamente das diásporas, como sustentam os transnacionalistas. Segundo a perspectiva teórica das redes, estes laços são, pelo contrário, o reflexo de uma experiência migratória que pode enriquecer notavelmente as iniciativas dos migrantes no seu retorno. Os recursos necessários para garantir um retorno bem-sucedido resultam, também, de padrões de relações interpessoais que, por sua vez, derivam de experiências migratórias passadas dos retornados.

As estruturas sociais aumentam a disponibilidade de recursos e informações e, ao mesmo tempo, asseguram a eficácia das iniciativas dos atores, ou seja, dos migrantes retornados. Portanto, a composição das redes, constituída por uma multiplicidade de estruturas sociais ${ }^{40}$, juntamente com a configuração dos laços, são de importância primária no exame dos princípios que definem e mantêm os vínculos transfronteiriços nos quais estão envolvidos os migrantes de retorno. Quando são analisados os laços transfronteiriços em termos de redes, não existe nenhum atributo categórico pré-estabelecido que permita traçar os princípios sobre os quais se fundam as dinâmicas das redes.

Ainda, os teóricos das redes sociais não consideram como dado de fato o pertencimento a uma rede: em primeiro lugar, porque as redes são organizadas de maneira seletiva ${ }^{41}$; em segundo lugar, porque o pertencimento pressupõe um ato voluntário por parte do próprio sujeito e o consenso dos outros membros com a finalidade de garantir os fluxos de recursos, bem como a eficiência e a manutenção dos laços transfronteiriços. De fato, as redes sociais e econômicas transfronteiriças correspondem a "uma entidade social [que] existe sob forma de consciência subjetiva partilhada coletivamente" ${ }^{\prime 42}$. É preciso acrescentar que a formação e a manutenção das redes exigem a

\footnotetext{
${ }^{40}$ ECCLES Robert G.; NOHRIA, Nitin. Networks and Organizations. Structure, Form, and Action.

${ }^{41} \mathrm{CHURCH}$, Madeline et alii. Participation, Relationships and Dynamic Change: New Thinking On Evaluating the Work of International Networks, p. 32.

${ }^{42}$ LAUMANN, Edward et alii. The Boundary Specification Problem in Network Analysis, p. 21.
} 
existência de relações pessoais de longa duração, bem como a regular troca entre atores de itens mutuamente valiosos. Este padrão de troca se mantém graças à circularidade inerente a estas redes.

Todavia, deve-se notar que outros recursos também são importantes para o bom êxito das iniciativas e dos projetos dos migrantes, no momento do regresso. Pode-se afirmar que a disponibilidade desses recursos esteja vinculada ao capital social do qual se beneficiavam os migrantes de retorno antes de se transferirem ao exterior. Por um lado, a experiência migratória vivida não pode sozinha explicar de modo exaustivo as iniciativas de quem retorna. Por outro lado, em termos de capital social, os migrantes de retorno não constituem um grupo homogêneo. O capital social que, no dizer de James Coleman, "é inerente à estrutura de relações entre vários atores" deve ser visto como um conjunto de recursos fornecidos às famílias dos migrantes de retorno. Em outros termos, os recursos sociais e financeiros pré-existentes, que são fornecidos pela família, podem impactar no êxito de quem regressa à pátria. $\mathrm{O}$ capital social constitui um dos recursos dos quais os retornados podem se beneficiar. É razoável pensar que o capital social, juntamente com a potencial participação dos migrantes de retorno nas redes sociais transfronteiriças, possam ser considerados um conjunto de recursos que se completam e configuram reciprocamente.

Fundamentalmente, os migrantes de retorno - sejam eles altamente especializados ou não, migrantes econômicos ou refugiados - devem ser considerados como atores em condições de encontrar meios úteis que assegurem a própria reentrada na pátria e capazes de participar das dinâmicas das redes transfronteiriças. As redes sociais nas quais eles estão inseridos constituem sistemas de relações sociais, baseados em pressupostos comunitários ou associativos. Os primeiros referem-se às relações de longa duração entre pertencentes das redes, cujas relações de troca são influenciadas por seus conteúdos relacionais. Os segundos fazem referência a um grupo seletivo de atores cujas relações são definidas em termos de pertencimento associativo.

Quer tenham bases comunitárias ou associativas, as características organizacionais das redes sociais e econômicas transfronteiriças são sensíveis ao contexto econômico, social e político dos países de origem e de destino. A referência à Teoria das Redes Sociais permite preencher a lacuna existente entre a estrutura organizacional das redes e o conteúdo relacional que os autores atribuem ao seu próprio envolvimento e pertencimento. A Teoria das Redes articula dois níveis de estudo.

\footnotetext{
${ }^{43}$ COLEMAN, James. Social Capital in the Creation of Human Capital, p. S110.
} 
Em primeiro lugar, os migrantes retornados são vistos como atores sociais centrais de um conjunto relacional ramificado. Uma atenta análise da prática de pertencimento às redes pode, de fato, revelar uma multiplicidade de envolvimentos por parte destes atores bem como uma variedade de modalidades organizativas que incidem sobre seus comportamentos. Em segundo lugar, em um determinado contexto, diversas estruturas de rede oferecem diferentes oportunidades, bem como diferentes estratégias e orientações. Tal multiplicidade de opções pode explicar o interesse dos atores e, ao mesmo tempo, garantir a continuidade das redes.

A diferença entre as redes sociais e econômicas transfronteiriças e as relações transnacionais parece clara em termos de padrões organizativos, objetivos e configuração. As redes possuem afinidade com "um tipo específico de relações que liga um grupo definido de pessoas, objetos ou eventos [...]. O conjunto de pessoas, objetos ou eventos no qual a rede é definida [...] possui alguns atributos distintos que os identificam como membros pertencentes à mesma classe de equivalência com o propósito de determinar a rede de relacionamentos existente entre eles". ${ }^{44} \mathrm{~A}$ importante definição formulada por David Knoke e James Kuklinski ressalta a necessidade de considerar o conteúdo relacional dos laços reticulares que sustentam a estrutura da rede, à qual os atores, isto é os migrantes de retorno, podem pertencer.

Ademais, os migrantes retornados são vistos como atores que atribuem um significado subjetivo a suas ações radicadas em um determinado contexto. De fato, as relações de rede podem basear-se no princípio de "complementaridade" 45 , que pode ocorrer em uma situação na qual os atores, que diferem entre si em termos de acesso aos recursos, características pessoais e especificidades inscritas, decidem entrar em uma parceria que seja de benefício mútuo. Há a necessidade também de considerar a consciência que os migrantes de retorno possuem de seu próprio envolvimento na rede, com especial atenção ao fato de que sua visão de mundo gera uma determinada forma de ambiente intelectual, traço distintivo que os migrantes de retorno gostam de cultivar.

Esta opinião remete às pesquisas realizadas por Phillips e Potter ${ }^{46}$ e por Elizabeth Thomas-Hope ${ }^{47}$, que entrevistaram, respectivamente, migrantes de retorno em Barbados e na Jamaica. A diferenciação está longe de ser irrelevante, pois origina, com certeza, os sentimentos de pertencimento a uma determinada

\footnotetext{
${ }^{44}$ KNOKE, David; KUKLINSKI, James H. (eds). Network Analysis, p. 12; THOMPSON, Grahame et alii. Markets, Hierarchies, and Networks: the Coordination of Social Life.

${ }^{45}$ LAUMANN et alii, Community Structure as Interorganizational Linkages, p. 462.

${ }^{46}$ PHILLIPS, Joan L.; POTTER, Robert B. Social Dynamics of Foreign Born and Young Returning Nationals to the Caribbean: A Review of the Literature.

${ }^{47}$ THOMAS-HOPE, Elizabeth. Return Migration to Jamaica and its Development Potential.
} 
"entidade" por parte dos migrantes de retorno ${ }^{48}$, o que não somente gera uma compreensão mútua e transmite pontos de referimento, mas também delimita os confins das redes sociais nos quais se movem os atores. Além disso, a diferenciação é parte integrante de um processo de identificação: essa não só consente evidenciar a consciência subjetiva dos atores que agem nas redes sociais e econômicas transfronteiriças, mas também põe em relevo o fato de que o desejo de fazer parte de determinadas relações sociais comuns permite traçar os confins das redes (entre aqueles que estão dentro e aqueles que estão fora) e pode gerar um mútuo entendimento.

Sem dúvida, quando se analisa a configuração das redes sociais transfronteiriças, é preciso colocar especial atenção sobre o significado que os próprios atores atribuem ao seu envolvimento nas estruturas de rede. Igualmente, o modo como eles percebem sua posição no âmbito dos modelos de parceria parece incidir sobre o grau em que esses sujeitos se identificam subjetivamente com as próprias redes de relações sociais. Em outros termos, existem vários graus de embeddedness na rede assim como existem vários tipos de conteúdos relacionais.

A resenha das cinco abordagens teóricas criticamente apresentadas neste estudo e sintetizadas na Tabela 1 contribui para uma melhor compreensão do fenômeno da migração de retorno. Ainda que tais interpretações estejam centralizadas principalmente em aspectos econômicos desta última, em nível individual ou familiar (como na Economia Neoclássica e na NELM), ou nas micro ou macro dimensões (Estruturalismo, Transnacionalismo e Teoria das Redes Sociais), as várias modalidades por meio das quais o fenômeno do retorno foi analisado e seus protagonistas descritos se distinguem umas das outras em termos de níveis de análise e quadro de investigação.

Apesar dos contrastes existentes entre as várias modalidades interpretativas, cada uma delas descreve as várias fases de desenvolvimento e maturação que caracterizam os fluxos migratórios internacionais ${ }^{49}$. De fato, as precedentes análises das teorias de retorno evidenciam suas motivações econômicas e não econômicas do retorno e a necessidade de contextualizar esse fenômeno de modo apropriado. Existem vários fatores induzidos pela oferta e pela procura que impactam sobre as dinâmicas da migração internacional, assim como vários fatores a nível micro e macroeconômico que, em determinadas circunstâncias, provocam o retorno e caracterizam sua configuração. É dever do observador identificar os fatores que mais do que outros motivam o retorno e incidem sobre sua preparação.

\footnotetext{
${ }^{48}$ WEBER, Max. Sociological Writings, p. 16.

${ }^{49}$ MARTIN, Philips; WIDGREN Jonas. International Migration: Facing the Challenge.
} 
Teorizando sobre a migração de retorno: uma abordagem conceitual revisitada sobre migrantes de retorno

\section{Tabela 1: As teorias da migração de retorno}

\begin{tabular}{|c|c|c|c|c|c|}
\hline & $\begin{array}{c}\text { Economia } \\
\text { neoclássica }\end{array}$ & $\begin{array}{l}\text { New Economics of } \\
\text { Labour Migration }\end{array}$ & Estruturalismo & Transnacionalismo & \begin{tabular}{|c|}
$\begin{array}{c}\text { Teoria das Redes Sociais } \\
\text { Transfronteiriças }\end{array}$ \\
\end{tabular} \\
\hline $\begin{array}{l}\text { Migração de } \\
\text { retorno }\end{array}$ & $\begin{array}{l}\text { Aqueles que ficam } \\
\text { no país de destino } \\
\text { são os bem- } \\
\text { sucedidos. O } \\
\text { retorno é uma } \\
\text { anomalia, senão o } \\
\text { fracasso da } \\
\text { experiência } \\
\text { migratória. }\end{array}$ & $\begin{array}{l}\text { O retorno faz } \\
\text { parte do projeto } \\
\text { migratório (visto } \\
\text { como uma } \\
\text { "estratégia } \\
\text { calculada"). Ele } \\
\text { ocorre quando } \\
\text { os objetivos do } \\
\text { migrante são } \\
\text { alcançados no } \\
\text { país de destino. }\end{array}$ & $\begin{array}{l}\text { Dicotomia centro } \\
\text { /periferia. O retorno ao } \\
\text { país de origem ocorre } \\
\text { sem que haja mudanças } \\
\text { ou compensações nas } \\
\text { limitações estruturais nos } \\
\text { países de origem } \\
\text { periféricos. O retorno } \\
\text { também se baseia em } \\
\text { informações incompletas } \\
\text { sobre o país de origem. }\end{array}$ & $\begin{array}{l}\text { O retorno não é } \\
\text { necessariamente } \\
\text { permanente. Ele ocorre } \\
\text { quando são reunidos } \\
\text { recursos financeiros e } \\
\text { benefícios suficientes } \\
\text { para sustentar a família e } \\
\text { quando as "condições" } \\
\text { no país de origem são } \\
\text { favoráveis. Ele é } \\
\text { preparado. O retorno } \\
\text { tem fundo social e } \\
\text { histórico. }\end{array}$ & $\begin{array}{l}\text { O retorno é garantido } \\
\text { e sustentado por redes } \\
\text { transfronteiriças de } \\
\text { relações sociais e } \\
\text { econômicas que } \\
\text { transmitem } \\
\text { informações. Voltar } \\
\text { constitui apenas um } \\
\text { primeiro passo para a } \\
\text { conclusão do projeto } \\
\text { migratório. }\end{array}$ \\
\hline $\begin{array}{l}\text { O migrante } \\
\text { retornado }\end{array}$ & $\begin{array}{l}\text { Abarca o migrante } \\
\text { malsucedido que } \\
\text { não pôde } \\
\text { maximizar sua } \\
\text { experiência no } \\
\text { exterior. }\end{array}$ & $\begin{array}{l}\text { Abarca o } \\
\text { migrante bem- } \\
\text { sucedido cujos } \\
\text { objetivos foram } \\
\text { alcançados no } \\
\text { país de destino. } \\
\text { O retornado é } \\
\text { um } \\
\text { intermediário } \\
\text { financeiro e um } \\
\text { assalariado } \\
\text { visado. }\end{array}$ & $\begin{array}{l}\text { O retornado (migrante } \\
\text { que não é bem nem } \\
\text { malsucedido) leva de } \\
\text { volta economias ao país } \\
\text { de origem. Expectativas } \\
\text { de retorno são } \\
\text { reajustadas e adaptadas } \\
\text { ao contexto estrutural do } \\
\text { país de origem. } \\
\text { "Divergências } \\
\text { comportamentais" } \\
\text { ocorrem no retorno. } \\
\text { Somente o retorno por } \\
\text { doença, velhice, } \\
\text { aposentadoria e falta de } \\
\text { talento, ou seja, o custo } \\
\text { do retorno é reduzido. }\end{array}$ & $\begin{array}{l}\text { Pertence a um grupo } \\
\text { étnico (ou seja, a } \\
\text { consciência de diáspora) } \\
\text { globalmente disperso. } \\
\text { Experiência migratória } \\
\text { bem-sucedida antes de } \\
\text { retornar. O retornado } \\
\text { define estratégias para } \\
\text { manter a mobilidade } \\
\text { transfronteiriça e os } \\
\text { vínculos embutidos em } \\
\text { sistemas globais de } \\
\text { relações étnicas e } \\
\text { parentais. }\end{array}$ & $\begin{array}{l}\text { Um ator social que } \\
\text { tem valores, projetos e } \\
\text { sua própria percepção } \\
\text { do ambiente do } \\
\text { retorno. Reúne } \\
\text { informações sobre o } \\
\text { contexto e as } \\
\text { oportunidades nos } \\
\text { países de origem. Os } \\
\text { recursos são } \\
\text { mobilizados antes do } \\
\text { retorno. Pertence a } \\
\text { redes transfronteiriças } \\
\text { que envolvem } \\
\text { migrantes e não- } \\
\text { migrantes. }\end{array}$ \\
\hline $\begin{array}{l}\text { Motivações } \\
\text { dos } \\
\text { retornados }\end{array}$ & $\begin{array}{l}\text { A experiência } \\
\text { migratória falhou. } \\
\text { Precisa retornar } \\
\text { para o país de } \\
\text { destino. }\end{array}$ & $\begin{array}{l}\text { Apega ao lar e à } \\
\text { família. Metas } \\
\text { são atingidas. }\end{array}$ & $\begin{array}{l}\text { Apego ao lar e à família, } \\
\text { nostalgia. As motivações } \\
\text { são reajustadas de } \\
\text { acordo com as } \\
\text { realidades do mercado e } \\
\text { relações de poder do } \\
\text { país de origem. }\end{array}$ & $\begin{array}{l}\text { Apego ao lar e à família. } \\
\text { Laços familiares são } \\
\text { cruciais. Condições } \\
\text { sociais e econômicas do } \\
\text { retorno são percebidas } \\
\text { como suficientemente } \\
\text { favoráveis para motivar o } \\
\text { retorno. }\end{array}$ & $\begin{array}{l}\text { Inserido e moldado } \\
\text { por oportunidades } \\
\text { sociais, econômicas e } \\
\text { institucionais no país } \\
\text { de origem, bem como } \\
\text { pela relevância dos } \\
\text { seus próprios recursos. }\end{array}$ \\
\hline $\begin{array}{l}\text { Capital } \\
\text { financeiro }\end{array}$ & $\begin{array}{l}\text { Nenhuma renda } \\
\text { ou economia é } \\
\text { repatriada do } \\
\text { exterior. }\end{array}$ & $\begin{array}{l}\text { As remessas } \\
\text { consistem em } \\
\text { uma segurança } \\
\text { contra eventos } \\
\text { inesperados. } \\
\text { Ajuda os } \\
\text { membros da } \\
\text { família. }\end{array}$ & $\begin{array}{l}\text { Economias e remessas } \\
\text { não têm impacto real } \\
\text { sobre o desenvolvimento } \\
\text { do país de origem. Os } \\
\text { membros da família } \\
\text { monopolizam os } \\
\text { recursos financeiros. Não } \\
\text { há efeito multiplicador. }\end{array}$ & $\begin{array}{l}\text { Pensões e benefícios } \\
\text { sociais são parte das } \\
\text { remessas. Recursos } \\
\text { financeiros são usados } \\
\text { de acordo com as } \\
\text { condições institucionais } \\
\text { do país de origem. } \\
\text { Transforma a estrutura } \\
\text { econômica e política das } \\
\text { áreas de destino. }\end{array}$ & $\begin{array}{l}\text { Remessas e economias } \\
\text { constituem apenas um } \\
\text { tipo de recursos. } \\
\text { Podem ser investidos } \\
\text { em projetos produtivos } \\
\text { que visam garantir o } \\
\text { retorno. }\end{array}$ \\
\hline $\begin{array}{l}\text { Capital } \\
\text { humano }\end{array}$ & $\begin{array}{l}\text { As habilidades } \\
\text { adquiridas no } \\
\text { exterior } \\
\text { dificilmente } \\
\text { podem ser } \\
\text { repassadas no país } \\
\text { de origem. Capital } \\
\text { humano é } \\
\text { desperdiçado. } \\
\end{array}$ & $\begin{array}{l}\text { O desenvolvi- } \\
\text { mento de } \\
\text { habilidades varia } \\
\text { de acordo com } \\
\text { a probabilidade } \\
\text { de retorno. }\end{array}$ & $\begin{array}{l}\text { As habilidades } \\
\text { adquiridas no exterior } \\
\text { são desperdiçadas } \\
\text { devido a limitações } \\
\text { estruturais dos países de } \\
\text { origem. Status social não } \\
\text { muda. }\end{array}$ & $\begin{array}{l}\text { Habilidades } \\
\text { aperfeiçoadas e } \\
\text { experiência educacional } \\
\text { adquiridas no exterior } \\
\text { permitem uma } \\
\text { mobilidade ascendente. }\end{array}$ & $\begin{array}{l}\text { Habilidades adquiridas } \\
\text { no exterior, assim } \\
\text { como conhecimento, } \\
\text { experiências, contatos } \\
\text { e valores são fatores } \\
\text { que contribuem para } \\
\text { garantir um retorno } \\
\text { bem-sucedido. }\end{array}$ \\
\hline
\end{tabular}




\section{A necessidade de uma abordagem conceitual revisitada para o migrante de retorno}

Como mencionado acima, graças às perspectivas do Transnacionalismo e da teoria de redes sociais, o retorno deixou de ser visto como o fim do ciclo de migração; em vez disso, ele constitui uma etapa no processo de migração. Na verdade, apesar de reconhecer a influência de fatores micro e macroestruturais nos países de origem, os dois quadros teóricos argumentam que a manutenção dos vínculos entre os países de origem e de chegada promove a capacidade dos imigrantes de preparar e garantir o seu próprio retorno, ao contrário do que afirmam os estruturalistas. Contudo, as análises de tais vínculos diferem uma da outra. Enquanto os vínculos transnacionais surgem espontaneamente em um nível transfronteiriço, com base na semelhança de atributos tais como etnia e parentesco, a Teoria das Redes Sociais afirma que o surgimento de redes transfronteiriças entre os países de origem e de chegada é sensível a fatores contextuais e institucionais. Redes sociais e econômicas transfronteiriças estimulam relações de troca complementares entre atores, que podem ir além da semelhança de atributos acima mencionada. Na verdade, essas relações de troca são vistas como sendo baseadas em interesses comuns e não em atributos. A Teoria das Redes Sociais constitui um quadro mais amplo de análise que permite o reconhecimento da complexidade das questões da migração de retorno.

Tendo explicado a fecundidade analítica da Teoria das Redes Sociais, podem ser identificadas quatro razões básicas pelas quais precisamos de uma abordagem conceitual revisitada dos migrantes de retorno.

- Em primeiro lugar, a crescente diversidade inerente aos fluxos migratórios internacionais ${ }^{50}$ sugere que precisamos ampliar o quadro analítico e interpretativo da migração de retorno. Isto não deveria se referir apenas aos trabalhadores migrantes, qualificados ou não, mas também aos estudantes migrantes, solicitantes de asilo e refugiados.

- Em segundo lugar, o surgimento e a consolidação de blocos comerciais regionais, a nível global, tem favorecido a liberalização dos mercados, bem como o desenvolvimento do setor privado em muitas economias em desenvolvimento. Apesar da resistência potencial de interferência do Estado na maioria das economias em desenvolvimento, as reformas liberais em muitos países de origem de migrantes têm criado as bases para o aumento das atividades de negócios, não só para os não- migrantes, mas também para os migrantes em geral, e retornados em particular.

\footnotetext{
${ }^{50}$ STALKER, Peter. Migration Trends and Migration Policy in Europe, p. 169.
} 
- Em terceiro lugar, a mobilidade transfronteiriça tem sido sustentada por custos de transporte mais baratos, transformando o retorno em um processo de múltiplas etapas.

- Em quarto lugar, os meios de comunicação tecnológicos têm favorecido o desenvolvimento de fluxos de informação, bem como o fortalecimento dos vínculos transfronteiriços, entre os países de origem e de chegada, permitindo que os migrantes preparem melhor o seu retorno.

Essas quatro razões contribuem para a necessidade de rever nossas variáveis analíticas, reconhecendo que, em termos de experiências de migração, tempo de permanência no exterior, padrões de mobilização de recursos, status legal, motivações e projetos, os migrantes retornados constituem hoje um grupo extremamente heterogêneo de atores. Da mesma forma, seu impacto nos países de origem e o potencial para o desenvolvimento variam bastante.

$\mathrm{Na}$ verdade, como Rosemarie Rogers ${ }^{51}$ salientou, os retornados diferem substancialmente uns dos outros em termos das motivações do retorno. Seu artigo pioneiro, de fato, demonstrou não apenas que os motivos para retornar são altamente variegados, mas que eles tendem também a se sobrepor. Hoje, as motivações de retorno têm se diversificado conforme novas categorias de retornados são levadas em consideração. Na verdade, as abordagens acadêmicas para as motivações do retorno não abarcam apenas trabalhadores migrantes ${ }^{52}$, estudantes migrantes ${ }^{53}$, migrantes altamente qualificados ${ }^{54}$, empresários retornados ${ }^{55}$, mas também os refugiados e solicitantes de asilo ${ }^{56}$. Além disso, o alargamento gradual do espectro da migração de retorno não só implica em crescente diversidade de motivos de retorno, mas também na variedade de padrões de mobilização de recursos. Esses padrões são, certamente, reflexos das experiências de migração dos retornados no exterior, mas não somente isso. Eles também são sensíveis

\footnotetext{
51 ROGERS, op. cit.

52 KUBAT, op. cit.; KING, op. cit.

${ }^{53}$ GLASER, William A.; HABERS, Christopher G. The Migration and Return of Professionals.

${ }^{54}$ LOWELL, Lindsay B. Policy Responses to the International Mobility of Skilled Labour; McLAUGHAN, Gail; SALT, John. Migration Policies towards Highly Skilled Foreign Workers; IREDALE, Robyn; GUO, Fey. The Transforming Role of Skilled and Business Returnees: Taiwan, China and Bangladesh; VERTOVEC, Stephen. Transnational Networks and Skilled Labour Migration; CERVANTES, Mario; GUELLEC, Dominique. The Brain Drain: Old Myths, New Realities.

${ }^{55}$ CASSARINO, Jean-Pierre. Tunisian New Entrepreneurs and their Past Experiences of Migration in Europe: Networks, Resource Mobilisation, and Hidden Disaffection.

56 AL-ALI et alii, op. cit.; AMMASSARI, Savina; BLACK, Richard. Harnessing the Potential of Migration and Return to Promote Development: Applying Concepts to West Africa; GHOSH, Bimal. Introduction: Towards a New International Regime for Orderly Movements of People.
} 
a condições institucionais, políticas e econômicas específicas no lugar de origem, que precisam ser consideradas, quando se quer entender por que alguns retornados podem aparecer como atores de mudança em sua pátria, enquanto outros não.

\section{Mobilização de Recursos e Returnee's Preparedness}

No contexto deste estudo, argumenta-se que a propensão dos migrantes para se tornarem atores de mudança e desenvolvimento em seus países de origem depende do grau em que se deu a preparação de seu retorno. Para ser bem-sucedida, a preparação do retorno requer tempo, recursos e vontade por parte do migrante. Em outras palavras, existem vários graus de preparação do regresso, que diferem uns dos outros em termos de mobilização de recursos e preparedness. Como pré-requisito para a introdução do marco conceitual, preparedness e mobilização de recursos precisam ser mais bem explicadas e definidas.

A mobilização de recursos baseia-se nos conhecimentos acima mencionados da teoria da rede social e diz respeito a recursos tangíveis (ou seja, o capital financeiro) e intangíveis (ou seja, contatos, relacionamentos, habilidades, conhecimentos) que foram mobilizados durante a experiência migratória no exterior. A mobilização de recursos também inclui recursos que o migrante trouxe com ele antes de sair de seu país de origem (ou seja, o capital social). Na realidade, estes dois sub-grupos de recursos constituem a mobilização de recursos. Nem é preciso salientar que os padrões de mobilização de recursos variam de acordo com as experiências de migração dos migrantes retornados, bem como com as suas origens sociais.

Preparedness diz respeito não só à vontade do migrante de voltar para casa, mas também a sua readiness para voltar. Em outras palavras, returnee's preparedness se refere a um ato voluntário que deve ser suportado pela captação de recursos e informações suficientes sobre as condições de pós-retorno no lugar de origem (ou seja, a readiness). Claramente, returnee's preparedness vai além da base de livre escolha, que foi introduzida pelo Conselho da Europa ${ }^{57}$. Para reforçar a ligação entre a migração de retorno e o desenvolvimento no país de origem, o retorno não deve simplesmente ser visto como um ato voluntário por parte do migrante, mas, acima de tudo, como uma prova de readiness. A Figura 1 esclarece as formas pelas quais as noções mencionadas anteriormente interagem umas com as outras, sendo ao mesmo tempo reflexos das circunstâncias nos países de origem e de chegada.

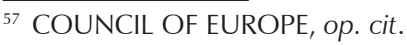


Figura 1 - Return Preparedness

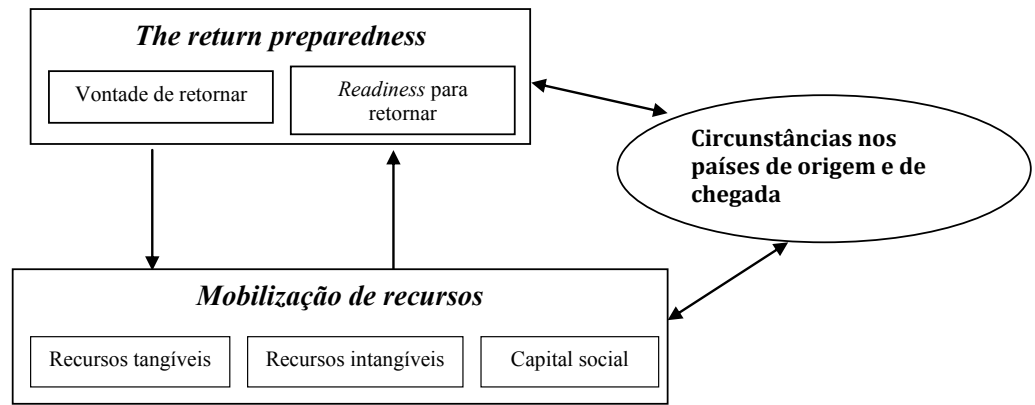

A ênfase na vontade e readiness do migrante para retornar (ou seja, returnee's preparedness) traz vários benefícios analíticos:

1. Argumenta-se que o retorno não é apenas um ato voluntário. Retorno também diz respeito a um processo de mobilização de recursos que exige tempo. Além disso, os migrantes podem manifestar o seu desejo de voltar, sem necessariamente estar prontos para retornar;

2. No que diz respeito à relação entre migração de retorno e desenvolvimento, mostra-se que, independentemente do seu status legal nos países de chegada, os retornados diferem uns dos outros em termos de níveis de preparedness e padrões de mobilização de recursos. Por exemplo, um trabalhador migrante, cuja experiência de migração tenha sido ótima ${ }^{58}$ (ou seja, não levou nem pouco nem muito tempo para investir no capital humano e financeiro adquirido no exterior) terá maior nível de preparedness do que o trabalhador migrante, cuja experiência de migração tenha sido muito curta para proporcionar return readiness. Da mesma forma, um migrante que tenha requerido e conseguido refúgio ou asilo no país chegada e cujo tempo de permanência tenha sido adequado, terá mais oportunidades para mobilizar recursos suficientes, tangíveis e intangíveis, para estar preparado para o retorno, do que um migrante que não tenha conseguido asilo ou refúgio;

3. Consideram-se vários tipos de migrantes que vão desde migrantes econômicos, migrantes qualificados e não qualificados, a refugiados. Em outras palavras, os migrantes retornados são diferentes uns dos outros, não só em termos de motivações, mas também em termos de níveis de preparedness e padrões de mobilização de recursos;

4. Mostra-se que returnee's preparedness não depende apenas da experiência do migrante no exterior, mas também da percepção de que mudanças institucionais, econômicas e políticas significativas ocorreram na

${ }^{58}$ KING, op. cit.; DUSTMANN, op. cit. 
própria pátria. Estas circunstâncias têm forte influência sobre a forma como os recursos são mobilizados e utilizados após o retorno;

5. Destaca-se o fato de que returnee's preparedness é moldada pelas circunstâncias nos países de origem e de chegada, ou seja, por condições de pré e pós-retorno;

6. Leva-se em consideração a preparedness do migrante para voltar, uma vez que se argumenta que o impacto dos retornados no desenvolvimento no país de origem depende de seu nível de preparedness.

Tabela 2 - Níveis de Returnee's Preparedness

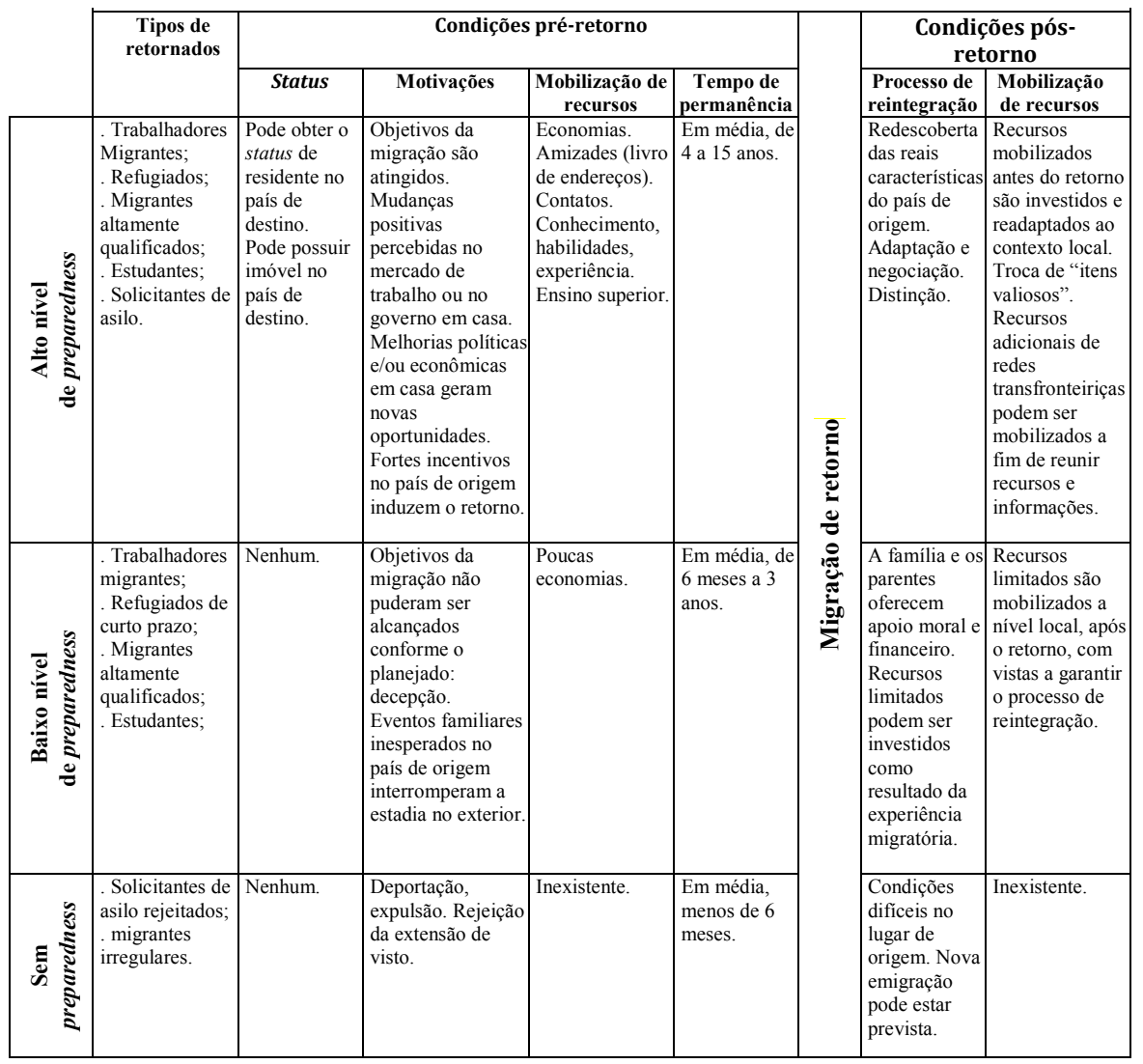

Tendo definido mobilização de recursos e preparedness do retornado, a Tabela 2 tem que ser vista como uma estrutura de análise que é útil na avaliação e compreensão do quanto os níveis de preparedness, os padrões de mobilização de recursos adotados por retornados, bem como condições pré e pós-retorno e o tempo médio de permanência no exterior impactam os processos de reintegração e o potencial de desenvolvimento no país de origem. 
Essa análise refere-se exclusivamente às pessoas que retornaram de seus países de destino. Ela inclui três níveis de preparedness que têm implicações sobre como os recursos, se houver, serão mobilizados antes e também após o regresso. Como mencionado acima, o impacto positivo da migração de retorno ao país de origem não é apenas uma questão de vontade por parte dos retornados, mas também (se não sobretudo) uma questão de padrões de preparação e mobilização de recursos, que são moldados de acordo com as condições pré e pós-retorno. Essa afirmação vai além da dicotomia sucessofracasso e sugere que sejam investigados os micro e macrofatores que configuram substancialmente os padrões de retorno e tornam os retornados potenciais agentes de desenvolvimento.

A primeira categoria se refere aos retornados cujo elevado nível de preparedness lhes permitiu organizar o seu próprio retorno de forma autônoma, enquanto foram mobilizados os recursos necessários para garantir o retorno. Essa categoria diz respeito aos migrantes que sentem que reuniram os recursos tangíveis e intangíveis suficientes para realizar seus projetos em seus países de origem. Eles também desenvolveram contatos valiosos e adquiriram habilidades e conhecimentos que podem constituir um complemento importante para as suas iniciativas. Eles tiveram tempo para avaliar os custos e benefícios de retorno, considerando as mudanças que ocorreram em seus países de origem, de caráter institucional, econômico e político. Alguns deles podem manter seu status residencial em suas antigas áreas de residência, com vistas a garantir a sua mobilidade transfronteiriça. Seu alto nível de preparedness influencia a sua participação em redes sociais e econômicas transfronteiriças; essas redes transmitem recursos informacionais e financeiros, que podem promover a mobilização de recursos, não só antes, mas também depois do retorno. Alguns projetos de migrantes no país de origem podem ser moldados por programas públicos, promovidos pelos governos dos países de origem, destinados a repatriar retornados qualificados e empresários. Embora o impacto de tais programas de retorno patrocinados pelo governo ainda necessite ser mais bem avaliado, a sua implementação pode ser vista como uma mudança positiva por parte dos retornados ${ }^{59}$. Muitas vezes, estes programas são acompanhados pela criação de zonas industriais e parques tecnológicos nos países de origem, com o objetivo de atrair investimentos diretos estrangeiros (IDE) e empresários retornados ${ }^{60}$.

\footnotetext{
${ }^{59}$ Isso é o que Robin Iredale e Fey Guo (IREDALE, GUO, op. cit., p. 14) observaram durante uma pesquisa relacionada a retornados chineses provenientes da Austrália. Os autores argumentam que "embora os programas de incentivos do governo chinês não pareçam ter impacto direto sobre o processo de tomada de decisão das pessoas na Austrália, eles têm gerado sinais positivos do governo de que o ambiente social e as políticas na China estão melhorando".

${ }^{60}$ CASSARINO, op. cit.
} 
A segunda categoria inclui os retornados que têm baixo nível de preparedness. Esta categoria diz respeito aos migrantes cuja duração da permanência no exterior foi muito curta para permitir que os recursos tangíveis e intangíveis fossem mobilizados devido a grandes acontecimentos que interromperam abruptamente suas experiências de migração, por exemplo, eventos familiares inesperados, ostracismo, falta de oportunidades reais de ascensão social e profissional no país de destino. Esses migrantes consideraram que os custos de se manter seriam maiores do que os de voltar para casa, mesmo que alguns recursos tenham sido mobilizados antes de seu retorno. Por isso, a mobilização de recursos nos países receptores permanece extremamente limitada e o retornado tende a contar com recursos disponíveis no país de origem, a fim de se reintegrar.

A terceira categoria se refere a retornados cujo nível de preparedness é inexistente. Na verdade, esses retornados não vislumbravam o retorno nem a preparação do retorno. Circunstâncias nos países de destino os levaram a partir, como, por exemplo, a rejeição do pedido de asilo ou a repatriação forçada.

\section{Conclusão}

Esta análise conceitual sugere que, devido à crescente diversidade dos retornados, é preciso abordar o fenômeno da migração de retorno com base em novas variáveis que expliquem como e em que circunstâncias os migrantes retornam. Claramente, como destacado por Bimal Ghosh, o retorno "é fortemente influenciado pelas motivações iniciais da migração, bem como pela duração da permanência no exterior e, particularmente, pelas condições em que o retorno ocorre ${ }^{\prime \prime 61}$. Os resultados apresentados na Tabela 2 confirmam seu argumento. Ao mesmo tempo, a referência para a returnee's preparedness (ver Figura 1) e os padrões de mobilização de recursos complementam o argumento de Ghosh. Esta dupla referência contribui para nossa compreensão de como e por que os retornados podem contribuir para estimular o desenvolvimento.

Esta abordagem conceitual revisitada nos induz a pensar que a questão não é tanto se concentrar exclusivamente na dimensão voluntária do retorno, quanto se deter ao nível de returnee's preparedness, ou seja, à sua vontade e readiness para retornar. Preparedness está longe de ser uma noção vaga; ela enfatiza a capacidade dos retornados de reunir recursos tangíveis e intangíveis quando o retorno ocorre de forma autônoma. Quanto maior o nível de preparedness maior será a capacidade dos retornados de mobilizar recursos de forma autônoma e mais intensa a sua contribuição

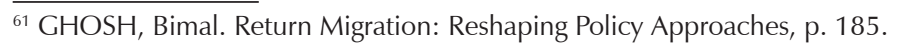


para o desenvolvimento. Além disso, os conhecimentos teóricos decorrentes da Teoria das Redes Sociais são fundamentais para compreender as maneiras pelas quais os retornados mobilizam seus recursos, sendo ao mesmo tempo envolvidos na dinâmica e manutenção de redes sociais e econômicas transfronteiriças. Essas redes não surgem espontaneamente, mas decorrem de condições específicas pré e pós-retorno. Elas também geram um continuum entre as experiências dos migrantes vividas nos países de destino e sua situação nos países de origem. Esse continuum diz respeito exclusivamente aos migrantes retornados que se beneficiam de um elevado nível de preparedness. Por outro lado, ele inexiste para os retornados que têm baixo ou nenhum nível de preparedness.

Essas observações são de suma importância para se compreender que a extensão e o tipo de experiências migratórias vividas no exterior têm uma determinada influência sobre os vários níveis de preparedness dos retornados e a sua capacidade potencial de contribuir para o desenvolvimento. Mais uma vez, as noções relativas à mobilização de recursos e à returnee's preparedness devem ser levadas em consideração caso se pretenda explicar as razões pelas quais alguns retornados acabam sendo agentes de desenvolvimento, enquanto outros não. O retorno consiste em um processo de preparação que pode ser perfeitamente investido em desenvolvimento, se ocorrer de forma autônoma e se a experiência de migração for longa o suficiente para promover a mobilização de recursos. Como a referida análise é aplicada no que diz respeito a essas observações? Primeiramente, ela reconhece que os fluxos migratórios internacionais alcançaram um grau de maturação que permite que o retorno seja preparado de forma autônoma, se as condições nos países de origem e destino forem favoráveis o suficiente para permitir que os recursos sejam mobilizados. Nesse sentido, resta demonstrado que a mobilização de recursos, que é inerente ao processo de preparação de retorno e depende da dinâmica das redes sociais e econômicas transfronteiriças, é um pré-requisito para se assegurar o retorno. Por fim, argumenta-se que o continuum é necessário para permitir que os recursos sejam mobilizados, não só antes, mas também depois do retorno.

\section{Bibliografia}

AL-ALI, Nadje; KOSER, Khalid (eds). New Approaches to Migration? Transnational Communities and the Transformation of Home. London: Routledge, 2002.

AL-ALI, Nadje; BLACK, Richard; KOSER, Khalid. The Limits of Transnationalism: Bosnian and Eritrean Refugees in Europe as Emerging Transnational Communities. Ethnic and Racial Studies, v. 24, n. 4, 2001, p. 578-600.

AMMASSARI, Savina; BLACK, Richard. Harnessing the Potential of Migration 
and Return to Promote Development: Applying Concepts to West Africa. IOM Migration Research Series, n. 5. Geneva: IOM, 2001.

BRAND, Laurie. States and Their Expatriates: Explaining the Development of Tunisian and Moroccan Emigration-Related Institutions. Working Paper n. 52. La Jolla: The Center for Comparative Immigration Studies, University of California-San Diego, 2002.

BYRON, Margaret; CONDON, Stephanie. A Comparative Study of Caribbean Return Migration from Britain and France: Towards a Context-Dependent Explanation. Transactions of the Institute of British Geographers, New Series, v. 21, n. 1, 1996, p. 91-104.

CALLEA, Saverio. Different Forms, Reasons and Motivations for Return Migration of Persons who Voluntarily Decide to Return to Their Countries of Origin. International Migration, v. 24, 1986, p. 61-76.

CASSARINO, Jean-Pierre. Tunisian New Entrepreneurs and their Past Experiences of Migration in Europe: Networks, Resource Mobilisation, and Hidden Disaffection. Aldershot: Ashgate Publishers, 2000.

CERASE, Francesco P. Expectations and Reality: A Case Study of Return Migration from the United States to Southern Italy. International Migration review, v. 8, n. 2, 1974, p. 245-262.

CERVANTES, Mario; GUELLEC, Dominique. The Brain Drain: Old Myths, New Realities. Paris: Directorate for Science, Technology and Industry, OECD, 2002.

CHAPMAN, Murray; PROTHERO, R. Mansell. Themes on Circulation in the Third World. International Migration Review, v. 17, n. 4, 1983-1984, p. 597-632.

$\mathrm{CHURCH}$, Madeline et alii. Participation, Relationships and Dynamic Change: New Thinking On Evaluating the Work of International Networks. Working Paper no. 121. London: University College of London, 2002.

COLEMAN, James. Social Capital in the Creation of Human Capital. American Journal of Sociology, suppl. 94, 1988, p. S95-S120.

COLTON, N. A. Homeward Bound: Yemeni Return Migration. International Migration Review, v. 27, n. 4, 1993, p. 870-882.

CONSTANT, Amelie; MASSEY, Douglas S. Return Migration by German Guestworkers: Neoclassical versus New Economic Theories. International Migration, v. 40, n. 4, 2002, p. 5-38.

COUNCIL OF EUROPE. Third Conference of European Ministers Responsible for Migration Affairs: Conclusions, 4 June 1987. MMG-3 (87) 22. Strasbourg: Council of Europe, 1987.

DUMON, Wilfried. Problems Faced by Migrations and their Family Members, Particularly Second Generation Migrants, in Returning to and Reintegrating into their Countries of Origin. International Migration, v. 24, 1986, p. 113-128.

DUSTMANN, Christian. Return Migration, Wage Differentials, and the Optimal Migration Duration. Discussion Paper, n. 264. Bonn: Institute for the Study of Labor, 2001.

ECCLES Robert G.; NOHRIA, Nitin. Networks and Organizations. Structure, Form, and Action. Boston: Harvard Business School Press, 1992. 
Teorizando sobre a migração de retorno: uma abordagem conceitual revisitada sobre migrantes de retorno

FAIST, Thomas. Transnationalization in International Migration: Implications for the Study of Citizenship and Culture. Bremen: Institute for Intercultural and International Studies WPTC-99-08, 1999.

GHOSH, Bimal. Introduction: Towards a New International Regime for Orderly Movements of People. In GHOSH, Bimal (ed). Managing Migration. Time for a New International Regime? Oxford: Oxford University Press, 2000, p. 6-26.

. Return Migration: Reshaping Policy Approaches. In GHOSH, Bimal (ed.).

Return Migration: Journey of Hope or Despair? Geneva: International Organization for Migration, 2000, p. 181-226.

GLASER, William A.; HABERS, Christopher G. The Migration and Return of Professionals. International Migration Review, v. 8, n. 2, 1974, p. 227-244.

GMELCH, George. Return Migration. Annual Review of Anthropology, v. 9, 1980, p. 135-159.

GUARNIZO, Luis Eduardo. Notes on Dual Citizenship, Nationalism, and Transnational Migration. Working Paper n. 5. New Haven: Yale Center for International and Area Studies, 1998.

HSING, You-Tien. Making Capitalism in China: The Taïwan Connection. New York: Oxford University Press, 1998.

IREDALE, Robyn. 2001. The Migration of Professionals: Theories and Typologies. International Migration Review, v. 39, n. 5, p. 7-24.

IREDALE, Robyn; GUO, Fey. The Transforming Role of Skilled and Business Returnees: Taiwan, China and Bangladesh. Wollongong: Centre for Asia Pacific Social Transformation Studies (CAPSTRANS), University of Wollongong (manuscript), 2001.

KING, Russel (ed.). Return Migration and Regional Economic Problems. London: Croom Helm, 1986.

KNOKE, David; KUKLINSKI, James H. (eds). Network Analysis. London: Sage Publications, 1982.

KRITZ, Mary M. International Migration Policies: Conceptual Problems. International Migration Review, v. 21, n. 4, 1987, p. 947-964.

KRITZ, Mary M.; LEAN LIM, Lin.; ZLOTNIK, Hania (eds.). International Migration Systems: A Global Approach. Oxford: Clarendon Press, 1992.

KUBAT, Daniel (ed.). The Politics of Return. International Return Migration in Europe. (Proceedings of the First European Conference on International Return Migration, Rome November 11-14, 1981). New York: Center for Migration Studies, 1984.

LAUMANN, Edward O.; MARSDEN, Peter V.; PRENSKY, David. The Boundary Specification Problem in Network Analysis. In BURT, Ronal; MINOR, Michael J. (eds.). Applied Network Analysis: A Methodological Introduction. London: Sage Publications Ltd., 1983, p. 18-34.

LAUMANN, Edward O.; GALASKIEWICZ, Joseph., MARSDEN, Peter V. Community Structure as Interorganizational Linkages. Annual Review of Sociology, v. 4, 1978, p. 455-484.

LEICHTMAN, Maria A. Transforming Brain Drain into Capital Gain: Morocco's 
Changing Relationship with Migration and Remittances. The Journal of North African Studies, v. 7, n. 1, 2002, p. 109-137.

LEVITT, Peggy. Forms of Transnational Community and their Implications for Immigrant Incorporation: Preliminary Findings. Paper presented at the Conference on Integrating Immigrants in Liberal States, Florence: European University Institute, European Forum, 8-9 May 1998, (Manuscript).

LEWIS, Jim; WILLIAMS, Allan. The Economic Impact of Return Migration in Central Portugal. In KING, Russel (ed.). Return Migration and Regional Economic Problems, London: Croom Helm, 1986, p. 100-128.

LOWELL, Lindsay B. Policy Responses to the International Mobility of Skilled Labour. Geneva: International Migration Branch, ILO, 2001.

MARTIN, Philips; WIDGREN Jonas. International Migration: Facing the Challenge. Population Bulletin, v. 57, n. 1, 2002, Washington: Population Reference Bureau.

McLAUGHAN, Gail; SALT, John. Migration Policies towards Highly Skilled Foreign Workers. London: Migration Research Unit, University College London, 2002.

MURPHY, Rachel. How Migrant Labor is Changing Rural China. Cambridge: Cambridge University Press, 2002.

PHILLIPS, Joan L.; POTTER, Robert B. Social Dynamics of Foreign Born and Young Returning Nationals to the Caribbean: A Review of the Literature. Reading: University of Reading. Geographical Paper n. 167, 2003.

PORTES, Alejandro. Introduction: The Debates and Significance of Immigrant Transnationalism. Global Networks, v. 1, n. 3, 2001, p. 181-193.

PORTES, Alejandro et alii. The Study of Transnationalism: Pitfalls and Promise of an Emergent Research Field. Ethnic and Racial Studies, v. 22, n. 2, 1999, p. 217-237.

RICHMOND, Anthony H. Explaining Return Migration. In KUBAT, Daniel (ed.). The Politics of Return. International Return Migration in Europe. New York: Center for Migration Studies, 1984, p. 269-275.

ROGERS, Rosemarie. Return Migration in Comparative Perspective. In KUBAT, Daniel (ed.). The Politics of Return. International Return Migration in Europe. New York: Center for Migration Studies, 1984, p. 277-299.

SCHNAPPER, Dominique. De l'Etat-nation au monde transnational. Du sens et de I'utilité du concept de diaspora. Revue Européenne des Migrations Internationales, v. 17, n. 2, 2001, p. 9-36.

STALKER, Peter. Migration Trends and Migration Policy in Europe. In VAN HEAR, Nicholas; NYBERG SØRENSEN, Ninna (eds.). The Migration-Development Nexus. Geneva: IOM, 2003, p. 159-187.

STARK, Oded. On the Microeconomics of Return Migration. Occasional Papers n. 1, 1996. Vienna: University of Vienna, ZIIS, 1996. . The Migration of Labor. Cambridge: Basil Blackwell, 1991.

STARK, Oded; GALOR Oded. Migrants' Savings, the Probability of Return Migration and Migrants' Performance. International Economic Review, v. 31, n. 2, 1990, p. 463-467. TAYLOR, J. Edward (ed.). Development Strategy, Employment and Migration: Insights 
Teorizando sobre a migração de retorno: uma abordagem conceitual revisitada sobre migrantes de retorno

from Models. Paris: OECD Development Centre, 1996.

THOMAS-HOPE, Elizabeth. Return Migration to Jamaica and its Development Potential. International Migration, v. 37, n. 1, 1999, p. 183-207.

THOMPSON, Grahame; FRANCES, Jennifer; LEVACIC, Rosalind; MITCHELL, Jeremy (eds.). Markets, Hierarchies, and Networks: the Coordination of Social Life. London: Sage Publications, 1991.

TODARO, Michael P. A Model of Labor Migration and Urban Unemployment in Less Developed Countries. The American Economic Review, v. 59, n. 1, 1969, p. 138-148.

VELIKONJA, Joseph. Geography of Return Migration. In KUBAT, Daniel (ed.). The Politics of Return. International Return Migration in Europe (Proceedings of the First European Conference on International Return Migration, Rome November 11-14, 1981). New York: Center for Migration Studies, 1984, p. 247-250.

VERTOVEC, Stephen. Transnational Networks and Skilled Labour Migration. Oxford: ESRC University of Oxford, 2002.

Conceiving and Researching Transnationalism. Ethnic and Racial Studies, v. 22, n. 2, 1999, p. 447-462.

WEBER, Max. Sociological Writings. New York: Continuum, 1994.

\section{Abstract}

\section{Theorising Return Migration: The Conceptual Approach to Return Migrants Revisited}

The diversity of migratory categories (ranging from economic migrants to refugees and asylum-seekers) necessitates a desegregation of the various types of returnees. We still need to know who returns when, and why; and why some returnees appear as actors of change, in specific social and institutional circumstances at home, while others do not. The first objective of this paper is to analyse how return has been dealt with by international migration theories, emphasising particularly the assumptions on which they rest. This theoretical overview is necessary to show how return has been defined and located in time and space, and how the returnee has been depicted. The second objective is to take the various approaches to return migration a step further by elaborating on the theoretical insights which have been extensively proposed so far. It will then present a revisited conceptual approach to returnees, taking into account a set of distinguishing criteria, i.e., "return preparedness" and "resource mobilisation".

Keywords: return migration, theories, preparedness return, resources, human capital, social networks.

Recebido para publicação em 18/10/2013.

Aceito para publicação em 23/11/2013.

Received for publication on October, 18 $8^{\text {th }}, 2013$.

Accepted for publication on November, 23 ${ }^{\text {th }}, 2013$.

ISSN impresso: 1980-8585

ISSN eletrônico: 2237-9843 